\title{
Grinding, Melting and Reshaping of EoL Thermoplastic Polymers Reinforced with Recycled Carbon Fibers
}

\author{
A. Donatelli, G. Casciaro, T. Marcianò, F. Caretto \\ ENEA - Italian National Agency for New Technologies, Energy and Sustainable Economic Development, SS \\ Appia 7, km 706.00, 72100 Brindisi, Italy \\ E-mail: antonio.donatelli@enea.it
}

Received: 26 April 2021; Accepted: 22 June 2021; Available online: 15 August 2021

\begin{abstract}
This article assesses the technical feasibility of a recycling process based on grinding, melting and reshaping of carbon fibers (CFs) reinforced thermoplastic polymers, in order to obtain new products that can be introduced in different markets, depending on mechanical properties retained. The idea at the basis of our study is that this kind of recycling process lies at the edge of the stages of recycling and re-use of materials, considering that the latter is preferable when considering the waste management hierarchy. Lower cost and similar mechanical strength of virgin CFs allowed the spread of recycled CFs in the automotive sector in the form of composite materials. Taking into account the Directive 2000/53/EC that sets out measures to prevent and limit waste from end-of-life (EoL) vehicles and their components, and ensures that where possible this is reused, recycled or recovered, we considered worth to investigate the recyclability of composite materials made with recycled CFs when they will reach the state of EoL materials. Considering this premise, an additional scope of this paper is therefore to provide some useful information about the possibility to perform a multiple closed loop recycling of rCF thermoplastic composites. Experiments carried out demonstrated that re-shaping of composites is technically feasible. Some square plates were produced without any setback. The mass balance of the recycling process demonstrated that about $88 \%$ of the EoL material can be recovered. Calculation of energy consumption showed that approximately $16 \mathrm{MJ}$ are necessary in the treatment of $1 \mathrm{~kg}$ of EoL composites.
\end{abstract}

Keywords: Composites; Thermoplastics; Carbon fibers; Recycling; EoL; Compression moulding.

\section{Introduction}

Composite materials based on polymers reinforced with carbon fibers (CFRPs) have been introduced since some decades in many industrial sectors, including automotive, aerospace, construction and wind farm [1-5] basically thanks to their ability to combine high mechanical performances with low weight when compared to traditional materials (steel above all). As a consequence, the global demand of carbon fibers was estimated up to 101 tons in 2016 and an annual growth rate of about $12 \%$ is expected in the next years, reaching a global demand of 194 tons in 2022 [6].

In particular, the advantages gathered in employing CFRPs in the automotive sector can include the reduction of fuel consumption and therefore of CO2 emissions [7]. Despite these advantages, the spread of CFRPs in many market shares, including automotive (apart from the luxury segment), was limited because the high cost of raw materials and of the manufacturing process of virgin carbon fibers make them very expensive $[8,9]$.

To overcome this setback, in the last years many scientific works have been done to evaluate the possibility to recover carbon fibers from End-of-life (EoL) composites and/or scraps. Scientific works demonstrated that carbon fibers can be recycled at a very low cost if compared to the production of virgin carbon fibers (18\$/kg to $26 \$ / \mathrm{kg}$ vs $33 \$ / \mathrm{kg}$ to $66 \$ / \mathrm{kg}$ ) [10]. This allows the use of composite based on carbon fibers to be enlarged into wider market segments.

In the last years, a lot of recycling process have been tested for CF based composite materials (mechanical grinding, conventional pyrolysis, microwave pyrolysis, high voltage fragmentation, solvolysis, combustion and incineration) [11-15]. Among these, actually the mechanical recycling process has been in depth analysed from several researchers [11, 16-21] and has achieved an average score of 6.3 in the TRL scale, indicating that prototypes demonstration in a relevant environment is reached as technology readiness [22].

Mechanical grinding is a process in which the material is milled to the level of powder by means of hammer mills or similar tools [19]. The obtained products are separated into two different fractions: one composed by large particles and typically rich in matrix fraction, which can be used an reinforcement in new composites, and one 
composed by finer particles, more rich in fiber fraction and which can be used as a filler in several applications [17].

However, at the moment there is no known mechanical grinding process for carbon fiber reinforced thermosetting composites exploited commercially; it is only used for resizing composite parts into chunks before feeding it into another process, such as pyrolysis [15].

In this work, a new approach in recycling of composites made with thermoplastic polymers and carbon fibers (CFRTP) has been proposed, aiming to provide additional novel elements toward the exploring of different approaches in recycling EoL composite materials. In particular, we investigated the possibility to re-shape EoL components, by combining mechanical recycling with moulding technologies. The idea at the basis of our choice is that this kind of approach can lie at the edge of the stages of recycling and re-use of materials, considering that the latter is preferable when we refer the waste management hierarchy. A project focused on a similar recycling process was carried out recently (TPC-Cyle) [23]. The project was focused on the optimum process and process settings to cost-effectively reprocess TPC waste. Scrap TenCate Cetex TC1100 woven carbon fiber/polyphenylene sulfide (CF/PPS) were used as composites. Authors claimed encouraging results, anyway no information were found. Our method presents some differences when compared to TPC-Cyle project, comprising the presence of a milling step before extrusion and a different thermoplastic resin (Polyamide 6).

The new products resulting from this kind of recycling process can be potentially used for the same or different applications, depending on mechanical properties retained.

In particular, a compression moulding technology is employed. For plastics, it was one of the first industrial methods. The basic process consists of heating polymers, under severe pressure, within a closed mould cavity. Under pressure the polymer liquefies and flows, taking the shape of the mould cavity, and then hardens into the desired part or product. Once sufficiently cooled and strong, the part is removed from the mould and the cycle is complete although the curing reaction continues while cooling to ambient (room) conditions [24].

Compression Moulding has already been utilised from researchers to produce polymers reinforced with recycled carbon fibers (rCFRPs) components from either random or aligned CF. They found that compression moulding random rCFRP part costs only 59-67\% of that for injection moulded random rCFRP part in the full life cycle. Moreover, the compression moulding random rCFRP part with higher fiber volume fraction (20-40\%vf) showed better mechanical performance than injection moulded part, which results in greater weight reductions relative to steel [25].

We focused our attention mainly on exploring the proposed approach from a technical point of view, investigating the possibility to re-melt and re-shape the composites, the mass balance of the process and the energy required in its implementation. A second part will follow, in which the attention will be focused on the mechanical properties retained, in view of market exploitation and identification of potential applications.

At last but not least, taking into account the Directive 2000/53/EC [26] that sets out measures to prevent and limit waste from end-of-life vehicles and their components, we found worth to investigate in particular the recyclability of thermoplastic polymers reinforced with recycled carbon fibers, in place of virgin ones (rCFRTP). An additional scope of this paper is therefore to provide some useful information about the possibility to perform a multiple closed loop recycling of rCF thermoplastic composites.

\section{Materials}

Materials submitted to the proposed recycling process were composites made with virgin polyamide 6 reinforced with $10 \mathrm{wt} \%$ of recycled carbon fibers (vPA6/rCF) in the form of glove compartments. They were manufactured by FCA Group using the injection moulding technology, within the REVALUE Project and therefore specifically made for this study.

RADILON S27 100 NT provided by RADICI Group was used as virgin polyamide 6. ELG Carbon Fiber Ltd. provided recycled carbon fibers reclaimed by pyrolysis of EoL composite materials, having an average length and diameter of about $6 \mathrm{~mm}$ and $5.4 \mu \mathrm{m}$, respectively.

\section{Recycling Process}

The recycling method investigated is based on a multi-step process aimed at giving new shape to end of life composite materials.

First of all, the glove compartments were heated up to $120^{\circ} \mathrm{C}$ for 200 hours in a GHIBLI laboratory oven, according to an internal recipe suggested by project partner Centro Ricerche Fiat, with the aim to simulate the natural aging they undergo to during the lifespan. Then the recycling process under investigation took place.

The moulding of composites is feasible if materials are in the form of powder, therefore a grinding step is necessary. Grinding is preceded by shredding, in order to reduce the average size of materials, which dimensions 
are commonly in the order of tens of centimeters. The glove compartments were therefore shredded down to chunks below $50 \mathrm{~mm}$ by means of water cooled band sawing machine MEP model PH261-1,

Particular attention must be paid to the grinding step. Indeed, grinding of materials will be performed taking into account that the ultimate average size of milled materials influences the final average length of carbon fibers. It has been demonstrated that the strength of composites is strictly related to the length of fibers. In particular, the strength of composites increases rapidly with the increase of the mean fiber length at small mean fiber lengths [27]. Considering this evidence, together with the efforts that one has to put in place in order to reduce as much as possible the formation of suspended dust during the operations, it is important to avoid excessive grinding of composites. On the other hand, if particle diameter is high it can be difficult to carry out the extrusion step, because of difficulties in drive the material along the screw or in assuring a complete melting of milled materials. As a consequence, a reasonable compromise has to be chosen and for technical reasons it is not possible to significantly change the average size of the particles. On the basis of the above information, the chunks obtained from shredding were grinded further down into fragments by means of a cutting mill RETSCH model SM300 (Table 1) and using a sieve with square holes of $2 \mathrm{~mm}$.

Therefore, at the end of the grinding, the materials appeared in granular form with an average size of $2 \mathrm{~mm}$ (Figure 1a).

Table 1. Main features of the Cutting Mill RETSCH model SM300.

\begin{tabular}{ll}
\hline Applications & Size reduction by cutting \\
Feed material & Soft, medium-hard, tough, elastic, fibrous \\
Size reduction principle & Shearing, cutting \\
Material feed size & $<60 \times 80 \mathrm{~mm}$ \\
Speed & $100-3000 \mathrm{rpm}$ \\
Rotor peripheral speed & $4.7-20.3 \mathrm{~m} / \mathrm{s}$ \\
Rotor diameter & $129.5 \mathrm{~mm}$ \\
Types of rotors & Parallel section rotor $/ 6$-disc rotor/V-rotor \\
Sieve sizes & Square holes $2.00 / 4.00 / 6.00 / 8.00 / 10.00 / 20.00 \mathrm{~mm}$ \\
Drive power & $3 \mathrm{~kW}$ \\
\hline
\end{tabular}

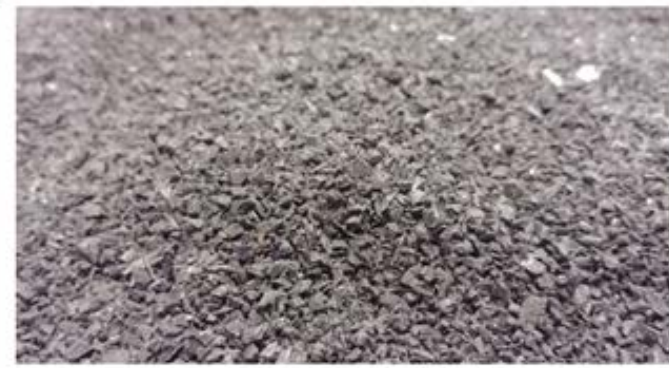

(a)

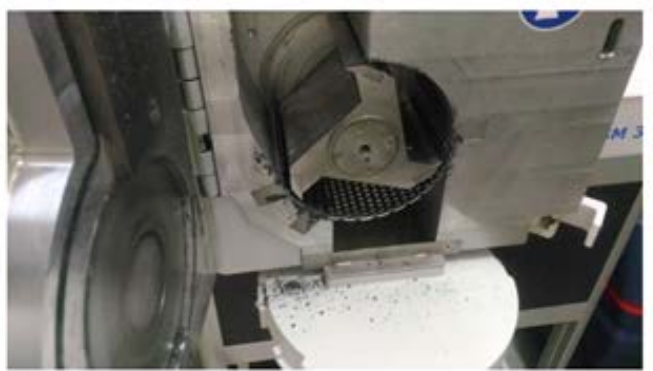

(b)

Figure 1. Grinded material (a) and a detail of the cutting mill RETSCH model SM300 (b).

A thermogravimetric analysis (TGA) of grinded materials was then performed, providing a moisture content of 2.13\%. It is important to underline that all Nylon plastic particles, like PA6, should be dried to a moisture content of less than $0.2 \%$ before they will be used to moulding step. Indeed, when moisture content exceeds $0.2 \%$, jet surfaces will be formed on product surfaces and spoil the exterior appearance. This undesirable event can negatively affect the mechanical properties of final moulds. With the aim to avoid this problem, the material was dried in a vacuum oven model BICASA B.E. 75 at $105^{\circ} \mathrm{C}$ and for 8 hours and subsequently was cooled down to the room temperature while kept into the vacuum oven, in order to prevent the contact with air. TGA analysis performed after the drying step provided a residual moisture content of $0.22 \%$, in line with the threshold above highlighted.

After the shredding, grinding and drying steps, the materials are extruded in order to obtain compounds that will be melted and shaped using rigid frames.

The grinded materials were therefore fed in a Thermo Scientific ${ }^{\mathrm{TM}}$ Rheomex $^{\mathrm{TM}}$ 19/25 OS extruder which technical features are highlighted in Table 2.

Downstream the extruder, some Post-ex (post extrusion) equipment were present to produce pellets by means of "spaghetti cutting" method: the molten composite was continuously discharged from a die and formed continuous filaments that, entrained by gears, were cooled in a water tank and were then cut at a low temperature by a pelletizer consisting in rotating knives (Figure 2). 
Table 2. Main features of the Thermo Scientific ${ }^{\mathrm{TM}}$ Rheomex $^{\mathrm{TM}}$ 19/25 OS extruder.

\begin{tabular}{ll}
\hline Max. Temperature & $450{ }^{\circ} \mathrm{C}$ \\
Measuring sensors & Melt temperature \\
Screw type & Single screw \\
Screw diameter & $19.05 \mathrm{~mm}$ \\
Max. screw speed & $250 \mathrm{rpm}$ \\
Temperature control zones & 4 \\
Heating zones & 4 \\
Screw type & Single screw \\
\hline
\end{tabular}

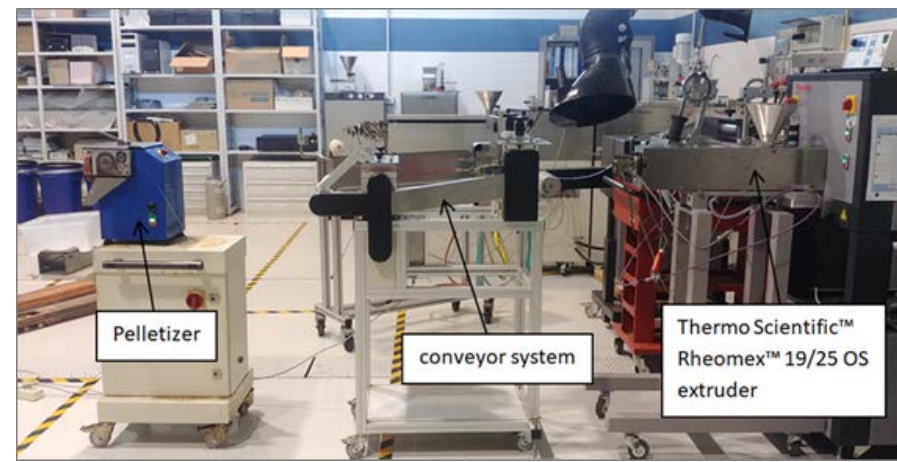

Figure 2. Extruder and post-extrusion equipment.

The extruder was equipped with four heaters: three of them were installed along the screw direction and one at the die section. The temperatures were chosen by performing a series of attempts, until the best condition in terms of fluidity and proper formation of the filaments were found. The best condition was found when all the sections were kept at $240{ }^{\circ} \mathrm{C}$ and the screw rotational speed settled at 20 RPM. Also in this case, the process parameters (the temperatures of the heated sections and the screw rotational speed) cannot be varied without encountering process issues.

The compression moulding of pellets was performed in a COLLIN P 300 P/M laboratory platen press (Figure 3a), which technical features are highlighted in Table 3.

Table 3. Main features of the COLLIN P 300 P/M platen press.

\begin{tabular}{ll}
\hline Plate dimensions & $300 \times 300 \mathrm{~mm}^{2}$ \\
Max. force & $200 \mathrm{kN}$ \\
Max. temperature & $300{ }^{\circ} \mathrm{C}$ \\
up to $15 \mathrm{~K} \cdot \mathrm{min}^{-1}$ & $>30 \mathrm{~K} \cdot \mathrm{min}^{-1}$ \\
Cooling rate & $\begin{array}{l}\text { The press is equipp } \\
\text { of the laminating }\end{array}$ \\
Special features &
\end{tabular}

(a)

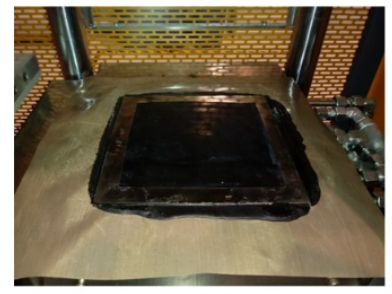

(c)

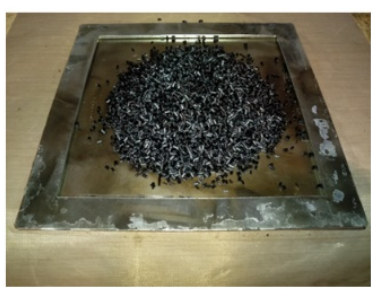

(b)

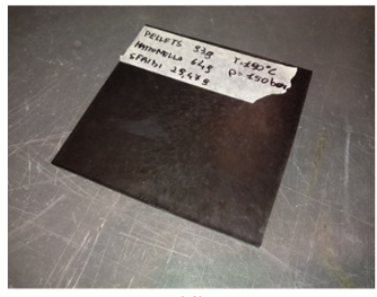

(d)

Figure 3. COLLIN P 300 P/M platen press (a), extruded material loaded within a squared rigid frame (b), final product before (c) and after (d) deflashing for sprue removal. 
A squared rigid frame was used to realize some square plates: pellets was charged into the frame (Figure 3b) and then placed inside the platen press. The compression moulding taken place by keeping the temperature constant at $240{ }^{\circ} \mathrm{C}$ and increasing the pressure from 50 to 150 bar. Moulding duration was 23 minutes, then the moulded was extracted from the platen press (Figure 3c) and sprue materials due to flashing were removed (Figures 3d).

The recipe of the moulding step was chosen based on experience and knowledge gained on similar materials in previous trials, and taking into account the molten temperature of PA6 declared on the datasheet $\left(240{ }^{\circ} \mathrm{C}\right)$.

\section{Result and discussion}

All the previous steps were carried out without any setbacks. Table 4 summarizes the process parameters for the overall recycling process. Five square moulds of recycled composites were manufactured, having a size of $160 \times 160 \times 3 \mathrm{~mm}$, demonstrating that the investigated recycling process has proven to be able to manufacture new recycled products, starting from EoL components.

In addition, the method has been applied on composites made with recycled carbon fibers, therefore an additional result of this work has been the demonstrating that rCF thermoplastic composites can be submitted to a multiple closed loop recycling step. The overall recycling process, with initial, final and intermediate products, is depicted in Figure 4.

Table 4. Process parameters of mechanical recycling process.

\begin{tabular}{lll}
\hline Accelerated aging & Equipment & laboratory Oven GHIBLI \\
& Temperature & $120{ }^{\circ} \mathrm{C}$ \\
& Time & $200 \mathrm{~h}$ \\
\hline Shredding & Equipment & Band sawing machine MEP PH261 \\
& blade dimensions & $2450 \times 27 \times 0.9 \mathrm{~mm}$ \\
\hline Grinding & Equipment & cutting mill RETSCH model SM300 \\
& Speed rotation & $700 \mathrm{RPM}$ \\
& Sieve size & $2.00 \mathrm{~mm}$ \\
\hline Extrusion & Equipment & Thermo Scientific ${ }^{\mathrm{TM}}$ Rheomex ${ }^{\mathrm{TM}} 19 / 25$ OS \\
& TS1 & $240^{\circ} \mathrm{C}$ \\
& TS2 & $240^{\circ} \mathrm{C}$ \\
& TS3 & $240{ }^{\circ} \mathrm{C}$ \\
& TS-D1 & $240{ }^{\circ} \mathrm{C}$ \\
& $\mathrm{n}$ & $20 \mathrm{RPM}$ \\
\hline Compression & Equipment & COLLIN P 300 P/M laboratory platen press \\
\cline { 2 - 3 } Moulding & Temperature & $\mathrm{t}=720 \mathrm{~s} @ \mathrm{~T}=240{ }^{\circ} \mathrm{C}$ \\
& program & $\mathrm{t}=400 \mathrm{~s} @ \mathrm{~T}=30^{\circ} \mathrm{C}$ \\
\cline { 2 - 3 } & Pressure program & $\mathrm{t}=300 \mathrm{~s} \mathrm{@} \mathrm{p}=0$ bar \\
& & $\mathrm{p}=1 \mathrm{bar} / \mathrm{sec}$ up to $\mathrm{p}=50$ bar \\
& $\mathrm{t}=200 \mathrm{~s} @ \mathrm{p}=50 \mathrm{bar}$ \\
& $\mathrm{p}=1 \mathrm{bar} / \mathrm{sec}$ up to $\mathrm{p}=150$ bar \\
& $\mathrm{t}=650 \mathrm{~s} @ \mathrm{p}=150 \mathrm{bar}$ \\
\hline
\end{tabular}

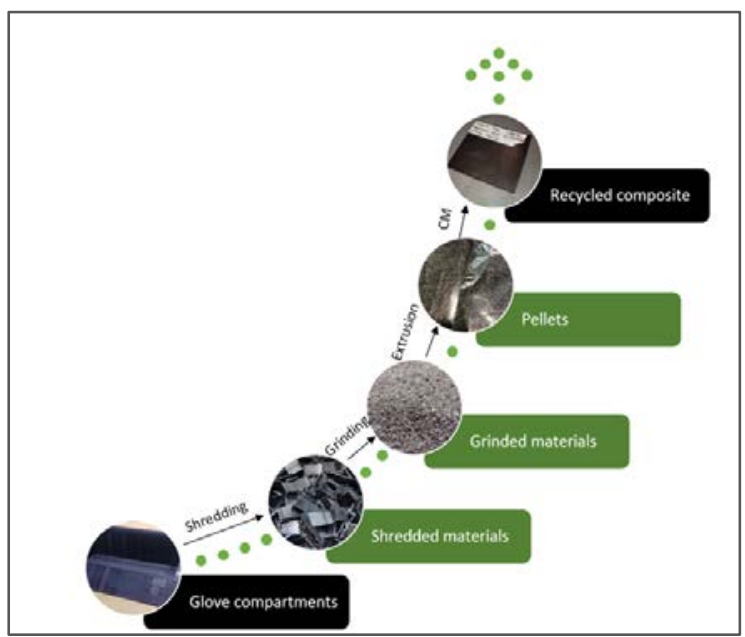

Figure 4. Outline of the implemented Recycling process. 
Five rectangular specimens were obtained from the manufactured square moulds and their density were measured by the displacement method based on the Archimedes' Principle: specimen were put into a graduated cylinder fill with water and the raising of the water level is measured through a caliper, in order to determine the volume of the specimen. The mass was measured by a laboratory scale and the density was determined as the ratio mass to volume. The same was done for specimens obtained from starting glove compartments. The results are highlighted in Figure 5, and compared with theoretical value determined on the basis of density of PA6 and carbon fiber and mass fraction $\left(1.183 \mathrm{~g} \cdot \mathrm{cm}^{-3}\right)$.

It is worth noting that both the initial and recycled composites have a lower density with respect to the theoretical one. This can be explained with the presence of voids that unavoidably are associated with the composite manufacturing process. This effect is more evident in the recycled process.

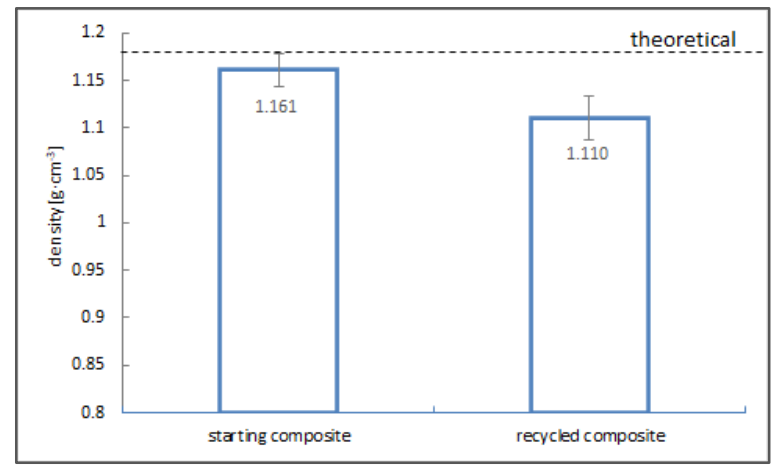

Figure 5. Comparison of theoretical, starting and recycled densities of composites.

\subsection{Mass balance}

In view of potential applications on industrial scale, the mass balance of the overall process was estimated (Table 5). Shredding \& grinding as well as extrusion were continuous process steps, therefore the mass balances were referred to the mass flow rate. Conversely, the compression moulding step was a batch step, therefore the mass balance was referred to processed masses.

Table 5. Mass balance of recycling process.

\begin{tabular}{llc}
\hline Shredding \& Grinding & $\dot{\mathrm{m}}_{\text {in }}\left[\mathrm{g} \cdot \mathrm{h}^{-1}\right]$ & 15000 \\
& $\dot{\mathrm{m}}_{\text {out }}\left[\mathrm{g} \cdot \mathrm{h}^{-1}\right]$ & 14892 \\
& $\mathrm{yield}(\%)$ & 99.3 \\
\hline Extrusion & $\dot{\mathrm{m}}_{\text {in }}\left[\mathrm{g} \cdot \mathrm{h}^{-1}\right]$ & 655 \\
& $\dot{\mathrm{m}}_{\text {out }}\left[\mathrm{g} \cdot \mathrm{h}^{-1}\right]$ & 650 \\
& $\mathrm{yield}(\%)$ & 99.2 \\
\hline Compression Moulding & $\mathrm{m}_{\text {in }}[\mathrm{g}]$ & 475.0 \\
& $\mathrm{~m}_{\text {out }}[\mathrm{g}]$ & 426.2 \\
& yield $(\%)$ & 89.1 \\
\hline Overall recycling process & yield $(\%)$ & $\mathbf{8 8 . 4}$ \\
\hline
\end{tabular}

From Table 5, it can be stated that negligible losses of materials were observed in the shredding \& grinding and extrusion. Material loss in shredding, and in particular in grinding, is related to the production of fine powders. With regard to this aspect, it is worth to underline the necessity to adopt any useful tool in order to preserve safety and health of any operators (presence of powder extractor).

Conversely, a greater loss of materials occurs in the compression moulding due to the removal of excess material which come out the rigid frame during the operation (deflashing), and resulting in yield of $89.1 \%$. Of course this value is strictly related to the form and the volume of the rigid frame used in moulding. As a rule one can state that the greater the volume of the product, and therefore of the frame, the lower the percentage of loss material in deflashing.

Considering all the previous steps, the overall yields of recycling process is quite high: $88.4 \%$.

\subsection{Energy requirement}

The recycling process has been evaluated also in terms of energy requirements. Specific energy consumption (SEC) required to carry out the steps of shredding \& grinding, extrusion and compression moulding have been measured and/or calculated based on process parameters adopted for the experimental activities. 


\subsubsection{Shredding \& grinding}

No direct measurements were performed for the evaluation of the energy required for shredding and grinding of composites, and the specific energy consumption for these steps was therefore estimated by resorting to formulations provided in Scientific Literature. In particular, it has been estimated as a function of the mass flow rate of treated composites, as follow [28]

$$
S E C_{g}=11.15 \cdot \dot{m}^{-0.76}
$$

where SECg is expressed in $\mathrm{MJ} \cdot \mathrm{kg}^{-1}$ if $\dot{m}$ is expressed in $\mathrm{kg} \cdot \mathrm{h}^{-1}$.

Equation 1 returns a value of $1.42 \mathrm{MJ} \mathrm{kg}^{-1}$, in line with Job et al. [15] which states that the energy demand of mechanical grinding of long fibers reinforced polymer composites lies between 0.1 and $4.8 \mathrm{MJ} \mathrm{kg}^{-1}$, depending on the used machinery and process scale.

\subsubsection{Extrusion}

The energy consumption during the extrusion process is the sum of two different contributes: the mechanical energy required to drive the material (driving), and the thermal energy required to melt and heat the material up to the process temperature (heating).

1) Driving

During the extrusion, the torque of the screw and its rotational speed were measured, from which the requested power and specific energy are determined by means of equations:

$$
\begin{aligned}
& P=T \cdot \frac{2 \pi}{60} n \\
& S E C_{d}=\frac{P}{\dot{m}}
\end{aligned}
$$

where, $T$ is Torque $[\mathrm{N} \cdot \mathrm{m}], n$ is rotational speed $\left[\mathrm{s}^{-1}\right], P$ is power $[\mathrm{W}]$ and $\dot{m}$ is mass flow rate $\left[\mathrm{kg} \cdot \mathrm{s}^{-1}\right]$.

Measured torque was $3.17 \mathrm{~N} \cdot \mathrm{m}$ from which a power of $6.64 \mathrm{~kW}$ and a $S C_{d}$ of $0.04 \mathrm{MJ} \cdot \mathrm{kg}^{-1}$ were calculated.

2) Heating

The thermal energy required for the heating of materials is determined based on the powers that the heaters supply during the experimental activities. The extruder includes three different $1 \mathrm{~kW}$ heaters along the screw. Another heater $(0.25 \mathrm{~kW})$ is present at the die section. Once the temperatures of the three sections, as well as that of the die section, were settled, a PID controller intervenes to establish to what percentage of their maximum load the heaters have to supply the thermal energy. The overall thermal energy is the sum of each heater contribute (Table 6), from which the SEC is determined as follows:

$$
S E C_{h}=\frac{P}{\dot{m}}
$$

The overall energy required for the extrusion of the material $\left(S E C_{e}\right)$ is the sum of the driving and thermal contributes, which gives a value of $2.80 \mathrm{MJ} \cdot \mathrm{kg}^{-1}$.

Table 6. Thermal energy demand in extrusion.

\begin{tabular}{lccccc}
\hline Zone & Heater & $\begin{array}{c}\text { Max power } \\
{[\mathrm{kW}]}\end{array}$ & $\begin{array}{c}\text { Actual power } \\
(\%)\end{array}$ & $\begin{array}{c}\text { Actual Power } \\
{[\mathrm{kW}]}\end{array}$ & $\begin{array}{c}\mathrm{SEC}_{\mathrm{h}} \\
{\left[\mathrm{MJ}^{-1} \mathrm{~kg}^{-1}\right]}\end{array}$ \\
\hline Section 1 & $\mathrm{Y}_{1}$ & 1.00 & 21.8 & 0.22 & 1.25 \\
Section 2 & $\mathrm{Y}_{2}$ & 1.00 & 6.8 & 0.07 & 0.39 \\
Section 3 & $\mathrm{Y}_{3}$ & 1.00 & 10.9 & 0.11 & 0.62 \\
Die & $\mathrm{Y}_{\mathrm{D} 1}$ & 0.25 & 35.4 & 0.09 & 0.51 \\
Overall heating & & & & 0.48 & $\mathbf{2 . 7 6}$ \\
\hline
\end{tabular}

Abeykoon et al. [29] found that the energy consumptions of extrusion of polymers such virgin high density polyethylene (HDPE) and virgin polystyrene (PS) lie in the range of $1.2-2.0 \mathrm{MJ} \cdot \mathrm{kg}^{-1}$, with the same rotational speed of the screw (20 RPM) but a little lower temperatures of barrel zones. This is comparable with value we obtained.

On the other hand, Anderson et al. [30] argued that the majority of polymeric materials demand specific energy lies between 0.0822 and $0.1644 \mathrm{kWh} \cdot \mathrm{kg}^{-1}$ (equivalent to $0.30-0.59 \mathrm{MJ} \cdot \mathrm{kg}^{-1}$ ) when they feed to the machine from room temperature. These values are lower than that we calculated despite the fact that PA6/CF composite has lower specific heat $\left(1.07 \mathrm{vs} 1.7 \mathrm{~kJ} \cdot \mathrm{kg}^{-1} \cdot \mathrm{K}^{-1}\right)$ and lower heat of fusion $\left(62.6 \mathrm{vs} 66.9 \mathrm{~kJ} \cdot \mathrm{kg}^{-1}\right)$ if compared to PA6. The specific heat of both PA6 and PA6/rCF were estimated by resorting in Literature data [30], meanwhile the 
heats of fusion were measured by DSC analysis performed in our laboratories and they are in good agreement with values reported in Literature [31, 33]. Differences in energy consumptions can in part be justified with high values of heat dispersed during the heating step, due to a defective insulation of the extruder.

\subsubsection{Compression moulding}

To manufacture CFRPs via compression moulding, energy is required to melt the compound (thermal energy), to compress the material up to the required pressure (kinetic energy) and for the subsequent steps of cooling and finishing.

Thermal energy is calculated based on the temperature profile, the specific heat $\left(c_{p}\right)$ and the latent heat of fusion of composite $\left(L_{f}\right)$ :

$$
S E C_{t}=c_{p} \cdot \Delta T+L_{f}
$$

Kinetic energy is determined based on pressing speed $(v)$, pressure ramp rate $(\dot{p})$ and ram area $\left(A_{0}\right)$, using the equation reported by Meng et al. [34]:

$$
S E C_{k}=\left(p A-p_{a} A_{0}\right) v \frac{p}{\dot{p}}
$$

The energy required for cooling and finishing are estimated from literature data and assumed equal to 0.9 $\mathrm{MJ} \cdot \mathrm{kg}^{-1}$ and $1.2 \mathrm{MJ} \cdot \mathrm{kg}^{-1}$, respectively [25].

The overall energy required for pressing by compression moulding $\left(S E C_{c m}\right)$ is the sum of the above-mentioned terms, which gives a value of $11.7 \mathrm{MJ} \cdot \mathrm{kg}^{-1}$.

Suzuki and Takahashi [35] state that the energy intensity of compression moulding applied on CFRPS is 10-13 $\mathrm{MJ} \cdot \mathrm{kg}^{-1}$, in line with our result. Conversely, Das [36] reported a value of $62.8 \mathrm{kWh}$ in compression moulding of CFRPs having a weight of $25.6 \mathrm{~kg}$; this is equivalent to $8.8 \mathrm{MJ} \mathrm{kg}^{-1}$. A bandwidth study on energy use in U.S. Carbon Fiber Reinforced Polymer Manufacturing [37] states that the typical energy intensity in compression moulding is $2632 \mathrm{BTU} \cdot \mathrm{lb}^{-1}$ (equivalent to $6.12 \mathrm{MJ} \cdot \mathrm{kg}^{-1}$ ). The value we obtained is a little higher of the aforementioned values, even if these studies referred to CFRPs with a higher mass fraction of carbon fibers (29 49 wt.\%).

Using equations (1) to (5), the SEC for the overall recycling process (SEC rec) has been determined (Table 7) and has been estimated to $15.9 \mathrm{MJ} \cdot \mathrm{kg}^{-1}$.

Table 7. Specific energy consumption of recycling process.

\begin{tabular}{llc}
\hline Shredding \& Grinding & $\mathrm{SEC}_{\mathrm{g}}\left[\mathrm{MJ} \cdot \mathrm{kg}^{-1}\right]$ & 1.42 \\
Extrusion & $\mathrm{SEC}_{\mathrm{e}}\left[\mathrm{MJ} \cdot \mathrm{kg}^{-1}\right]$ & 2.80 \\
Compression moulding & $\mathrm{SEC}_{\mathrm{cm}}\left[\mathrm{MJ} \cdot \mathrm{kg}^{-1}\right]$ & 11.67 \\
Recycling Process & SEC $_{\mathrm{rec}}\left[\mathrm{MJ} \cdot \mathrm{kg}^{-1}\right]$ & $\mathbf{1 5 . 8 9}$ \\
\hline
\end{tabular}

\section{Conclusions}

In the present work, a recycling process of carbon fiber reinforced thermoplastic polymers based on grinding, melting and re-shaping has been developed. Experimental activities showed that new products can be manufactured by means of the developed method and starting from EoL composites, without any setbacks.

In addition, the method has been applied on composites made with recycled carbon fibers, therefore an additional result of this work has been the demonstrating that rCF thermoplastic composites can be submitted to a multiple closed loop recycling step.

The method assures retains of materials, with an overall mass percentage yield of $88.4 \%$. Loss of materials are due at lesser extent to shredding \& grinding, because of fine powder formation, and especially to compression moulding, because of deflashing. It is worth to note that loss of materials in deflashing, and therefore the overall yield of the process, is strictly related to the geometry of rigid frames and the volume of final products. As a rule one can state that the greater the volume of the products, the lower the percentage of loss material in deflashing.

The recycling process has been studied also in terms of energy demand. The specific energy consumptions (SECs) of each single step process have been estimated. The more demanding step is confirmed to be the compression moulding, with values a little higher that those commonly referred to compression moulding of CFRP. The SEC of the overall recycling process has been calculated in the order of $15.9 \mathrm{MJ} \cdot \mathrm{kg}^{-1}$.

\section{Future work}


The proposed method appears technically feasible because allow the production of new products. Anyway, further studies to establish at what extent the mechanical properties of recycled materials are retained is necessary. Only based on this evidence one can address the materials toward potential applications, in view of possible market exploitation.

\section{Acknowledgements}

This work was supported by REVALUE Project (REcycled carbon fibers for high VALUE composites - Project Agreement number: 16211) funded by the European Institute of Innovation and Technology (EIT) Raw Materials.

The authors of the present work thank the colleagues of the Laboratory of Functional materials and technologies for sustainable applications in the ENEA Brindisi Research Centre. In particular, thanks goes to Mrs. Caterina Blasi and Mr. Saverio Mazzarelli, for their valuable collaboration in carried out the experimental tests, and to Mrs. Monica Schioppa for her precious collaboration in carrying out TGA and DCS analysis.

\section{References}

[1] Bai A, Wang Z, Feng L. Chemical recycling of carbon fibres reinforced epoxy resin composites in oxygen supercritical water. Materials \& Design. 2010;31:999-1002.

[2] Sims G, Bishop G. UK Polymer composites sector: foresight study and competitive analysis, DTI/OST. National Physical Laboratory. NPL Report MATC (A) 80. October 2001.

[3] Holmes M. Global carbon fibre market remains on upward trend. Reinforced Plastics. 2014;58:38-45.

[4] Grand View Research Inc. Carbon Fiber Market Analysis By Raw Material (PAN, Pitch), By Tow Size, By Application (Automotive, Aerospace \& Defense, Wind Turbines, Sport Equipment, Construction, Pressure Vessels), And Segment Forecasts 2018-2025. ID: GVR-1-68038-523-6. August 2017.

[5] Grand View Research Inc. Composites Market Size, Share \& Trends Analysis Report By Product (Carbon, Glass), By Resin, By Manufacturing Process, By Application, By End Use, And Segment Forecasts, 20182024. ID: 978-1-68038-917-3. July 2018.

[6] Witten E, Thomas M, Michael K. Composite Market 2015. Industrievereinigung Verstärkte Kunstoffe, 1-44.

[7] Tapper R J, Longana M L, Norton A, Potter K D,,Hamerton, I. An evaluation of life cycle assessment and its application to the closed-loop recycling of carbon fibre reinforced polymers. Composite Part B: Engineering. 2020; 184:107665.

[8] Park S, Seo M K. Chapter 7 - Types of Composites. Interface Science and Technology. 2011;18:501-629.

[9] Baker D A, Rials T G. Recent Advances in Low-Cost Carbon Fiber Manufacture from Lignin. Journal of Applied Polymer Science. 2013;130(2):713-728.

[10] Carberry W. Airplane Recycling Efforts benefit boeing operators. Boeing AERO Magazine QRT. 2008; 4:613.

[11] Pickering S J. Recycling technologies for thermoset composite materials_current status. Advanced Polymer Composites for Structural Applications in Construction. 2006;37:1206-1215.

[12] Pickering S J. Thermal methods for recycling waste composites. Management, Recycling and Reuse of Waste Composites. Woodhead Publishing Limited. 2009.

[13] Papadakis N, Ramírez C, Reynolds N. Designing composite wind turbine blades for disposal, recycling or reuse. Management, Recycling and Reuse of Waste Composites. 2009;443-457.

[14] Yang Y, Boom R, Irion B, Van Heerden D J, Kuiper P, De Wit H. Recycling of composite materials. Chemical Engineering and Processing: Process Intensification. 2012;51:53-68.

[15] Job S, Leeke G, Mativenga P T, Oliveux G, Pickering S J, Shuaib N A. Composites recycling: Where are we now? 2016.

[16] Kouparitsas C E, Kartalis C N , Varelidis P C, Tsenoglou C J, Papaspyrides C D. Recycling of the fibrous fraction of reinforced thermoset composite. Polym. Compos. 2002;23:682-689.

[17] Palmer J, Ghita O R, Savage L, Evans K E. Successful closed-loop recycling of thermoset composites. Compos. Part Appl. Sci. Manuf. 2009;40:490-498.

[18] Palmer J, Savage L, Ghita O R. Sheet moulding compound (SMC) from carbon fibre recyclate. Compos. Part Appl. Sci. Manuf. 2010;41:1232-1237.

[19] Job S. Composite Recycling, Summary of Recent Research and Development. 2010.

[20] Asmatulu E, Twomey J, Overcash M. Recycling of fiber-reinforced composites and direct structural composite recycling concept. Journal of Composite Material. 2014;48(5):593-608.

[21] Oliveux G, Dandy L O, Leeke, G A. Current status of recycling of fibre reinforced polymers: Review of technologies, reuse and resulting properties. Progress in Materials Science. 2015;72:61-99.

[22] Rybicka J, Tiwari A, Leeke G A. Technology readiness level assessment of composites recycling. Journal of Cleaner Production. 2016;112:1001-1012. 
[23] TPC-Cycle Project web site, accessed 20 $0^{\text {th }}$ April 2021. https://thermoplasticcomposites.nl/researchareas/recycling/project-tpc-cycle/

[24] Tatara R A. Compression Molding, Applied Plastics Engineering Handbook - Processing, Materials and Applications, Second Edition, Chapter 14. Plastic Design Library. 2017;291-320.

[25] Meng F, McKechnie J, Pickering S J. An assessment of financial viability of recycled carbon fibre in automotive application. Composite Part A. 2018;109:207-220.

[26] Directive 2000/53/EC of the European Parliament and of the Council of 18 September 2000 on end-of life vehicles - Commission Statements, accessed 20 ${ }^{\text {th }}$ April 2021. https://eur-lex.europa.eu/legalcontent/EN/TXT/HTML/?uri=CELEX:32000L0053\&from=IT.

[27] Fu S-Y, Lauke B. Effects of fiber length and fiber orientation distributions on the tensile strength of shortfiber-reinforced polymers. Composites Science and Technology. 1996;56(10):1179-1190.

[28] Howart J, Mareddy S S R, Mativenga P T. Energy intensity and environmental analysis of mechanical recycling of carbon fibre composite. Journal of Cleaner Production. 2014;81:46-50.

[29] Abeykoon C, Kelly A L, Brown E C, Vera-Sorroche J, Coates P D, Harkin-Jones E, Howell K B, Deng J, Li $\mathrm{K}$, Price $\mathrm{M}$. Investigation of the process energy demand in polymer extrusion: A brief review and an experimental study. Applied Energy. 2014;136:726-737.

[30] Anderson J, Rauwendaal C, Noriega MdelP, Troubleshooting extrusion problems. SPE ANTEC technical papers 1. 1997; 127-134.

[31] Guglhoer T, Korkisch M, Sause M G R. Influence of carbon fibers on the crystallinity of polyamide-6. 20th International Conference on Composite Materials. Copenhagen, 19-24 ${ }^{\text {th }}$ July 2015.

[32] Karsli N G, Aytac A. Tensile and thermomechanical properties of short carbon fiber reinforced polyamide 6 composites. Composite: Part B. 2013;51:270-275.

[33] Liu K, Li Y, Tao L, Xiao R. Preparation and characterization of polyamide 6 fibre based on a phosphoruscontaining flame retardant. RSC Advances. 2018;8:9261-9271.

[34] Meng F, McKechnie J, Turner T, Wong K H, Pickering S J. Environmental Aspects of Use of Recycled Carbon Fiber Composites in Automotive Applications. Environ. Sci. Technol. 2017;51(21):12727-12736.

[35] Suzuki T, Takahashi J. Prediction of energy intensity of carbon fiber reinforced plastics for mass-produced passenger cars. The Ninth Japan International SAMPE symposium. Nov. 29 - Dec. 2, 2005.

[36] Das S. Life Cycle Assessment of Carbon Fiber-Reinforced Polymer Composites. International Journal of Life Cycle Assessment. 2011;16:268-282.

[37] Bandwidth Study on Energy Use and Potential Energy Saving Opportunities in U.S. Carbon Fiber Reinforced Polymer Manufacturing. United States: N.p.2017. https://www.osti.gov/biblio/1513860-bandwidth-studyenergy-use-potential-energy-saving-opportunities-carbon-fiber-reinforced-polymer-manufacturing. Accessed 26 ${ }^{\text {th }}$ April, 2021.

(C) 2021 by the author(s). This work is licensed under a Creative Commons Attribution 4.0 International License (http://creativecommons.org/licenses/by/4.0/). Authors retain copyright of their work, with first publication rights granted to Tech Reviews Ltd. 